\title{
A Gall-Inducing Caterpillar Species Increases Essential Fatty Acid Content of Its Host Plant Without Concomitant Increases in Phytohormone Levels
}

\author{
John F. Tooker and Consuelo M. De Moraes \\ Department of Entomology, Center for Chemical Ecology, 501 ASI Building, The Pennsylvania State University, \\ University Park 16823, U.S.A.
}

Submitted 30 December 2008. Accepted 9 January 2009.

\begin{abstract}
Gall-inducing insects are accomplished plant parasites that can profoundly influence host-plant physiology. We recently reported that the caterpillar Gnorimoschema gallaesolidaginis failed to significantly alter emissions of host-plant volatiles that often recruit natural enemies of insect herbivores, and demonstrated that a caterpillar species feeding on linolenate-deficient plant tissues avoids inducing some of the indirect defenses of its host plant. Here, we investigate whether absence of volatile responses to the galler $G$. gallaesolidaginis could similarly be explained by a lack of linolenate in galls. We screened interior and exterior tissue of galls and control stems of Solidago altissima for free linolenate, linoleate, 12-oxo-phytodienoate, jasmonate, and salicylate. We found, unexpectedly, that $G$. gallaesolidaginis strongly increased amounts of linolenic and linoleic acids inside galls without associated increases in two downstream products, 12-oxo-phytodienoic or jasmonic acid. In contrast, the generalist caterpillar Heliothis virescens induced elevated levels of linolenic, linoleic, 12-oxo-phytodienoic, and jasmonic acids in S. altissima. Moreover, these two fatty acids and 12-oxo-phytodienoate were significantly and positively associated with jasmonic acid, suggesting that increased levels of these precursors can lead directly to greater amounts of jasmonic acid. Taken together, these findings suggest that gall insects may be able to nutritionally enhance their food source without inducing concomitant increases in phytohormones and associated defense responses.
\end{abstract}

Parasites can induce striking alterations of host physiology and morphology (Eigenbrode et al. 2002; Stone and Schönrogge 2003). In some cases, the induced changes can be considered adaptively evolved manipulations because they strongly benefit parasite fitness (Dawkins 1982; Thomas et al. 2002). In other cases, the changes are merely side effects of parasitism (Edelaar et al. 2003). Among plant parasites, gall-inducing insects are often assumed to manipulate their host plants adaptively because the galls they force their host plants to produce provide protection from natural enemies, a more suitable microenvironment, or improved nutrition (Raman et al. 2005). In addition to the often obvious morphological changes associated with gall formation, the influence of gall insects often extends to plant physiology and chemistry (Larson 1998; Nyman and Julkunen-Tiitto 2000; Stone and Schönrogge 2003). Chief among the chemical manipulations employed by gall insects is their ability to modify the distribution of plant secondary me-

Corresponding author: John Tooker; E-mail: tooker@psu.edu tabolites, altering concentrations of plant compounds for their own purposes such as attracting mates and avoiding plant toxins (Abrahamson and Weis 1987; Allison and Schultz 2005; Hartley 1998; Nyman and Julkunen-Tiitto 2000; Tooker and De Moraes 2007; Tooker and Hanks 2004; Tooker et al. 2002, 2008).

We recently reported that gall-inducing insect species feeding on wheat and goldenrod are, in some cases, capable of avoiding or altering the production of secondary metabolites involved in indirect plant defenses (Tooker and De Moraes 2007; Tooker et al. 2008). In particular, some gall-inducing insects fail to elicit the release of volatile compounds that are known to attract natural enemies of herbivores, including gallformers (De Moraes et al. 1998; Karban and Baldwin 1997; Tooker and Hanks 2006; Turlings et al. 1990). One of these defense-avoiding species is Gnorimoschema gallaesolidaginis (Riley), a gelechiid moth caterpillar that bores into stems of tall goldenrod, Solidago altissima L., inducing a spindleshaped gall (Miller 2000 provides biological details on this gall-inducing species). Feeding by larvae of this lepidopteran failed to increase volatile emissions of S. altissima whereas feeding by the generalist caterpillar Heliothis virescens L. triggered a strong release of volatiles from this goldenrod species (Tooker et al. 2008). Though herbivory by some nongalling insects (e.g., aphids) can fail to evoke significant volatile responses (Turlings et al. 1998), most caterpillar species elicit substantial volatile responses from their host plants because their feeding liberates linolenic acid (LNA) from plant membranes and induces enzymes that oxidize LNA via the octadecanoid pathway to form jasmonic acid (JA), a phytohormone that triggers volatile release (Conconi et al. 1996; Creelman and Mullet 1997; Hopke et al. 1994).

To our knowledge, only one other caterpillar species has been shown to circumvent some of the feeding-induced indirect defenses of its host-plant species, and does so by feeding on LNA-deficient fruit (De Moraes and Mescher 2004). Among lepidopteran larvae, this tactic is somewhat unique because LNA is an essential fatty acid that does not appear to be synthesized by most caterpillar species and must be acquired from their diet (Bracken 1982; Vanderzant 1968). No galling insects of any kind have been reported to feed upon tissue that is deficient in fatty acids (Bayer 1991; Motta et al. 2005); therefore, it has not previously been clear how galling insects are able to avoid inducing volatile emissions while satisfying their own nutritional requirements.

We initiated this study to determine whether the absence of volatile responses to feeding by the gall-inducing caterpillar G. gallaesolidaginis could be explained by a lack of LNA or 
linoleic aid (LA) in gall tissue. Linoleate has one less double bond than LNA and is also released from plant membranes upon caterpillar damage (Conconi et al. 1996). Like LNA, LA also appears to be essential for proper lepidopteran development and, unlike some other types of insects, caterpillars do not appear synthesize LA and need to obtain it via their diet (Cripps et al. 1986; Vanderzant 1968). To determine how $G$. gallaesolidaginis evades indirect defenses of $S$. altissima, we collected G. gallaesolidaginis galls and ungalled control stems weekly during the period of active gall growth, dissected them, and measured levels of free LNA, LA, JA, 12-oxo-phytodienoate (OPDA) (a precursor to JA), and salicylate (SA) (which can inhibit the activity of JA) (Doares et al. 1995; Felton et al. 1999). Some of our previous research addressed levels of JA and SA in mature galls of $G$. gallaesolidaginis from a single collection date (Tooker et al. 2008). The data we present here, however, are much broader, comprising eight collection dates spanning all stages of gall development, and provide a view of the developmental dynamics of these plant compounds. We also exposed lab-grown $S$. altissima to the polyphagous caterpillar $H$. virescens, which elicits a strong volatile response from S. altissima (Tooker et al. 2008). This experiment was included as a positive control to determine how levels of LNA, LA, OPDA, JA, and SA change when S. altissima is attacked by a generalist herbivore.

\section{RESULTS}

\section{Levels of LNA, LA, OPDA, JA, and SA}

in $H$. virescens-damaged $S$. altissima.

To determine how S. altissima responds to a generalist caterpillar species, growth-chamber-grown $S$. altissima were exposed to the generalist caterpillar $H$. virescens (Fabricius). This species does not regularly feed on Solidago spp. but will do so if starved and so can be used as a tool to elicit plant defensive responses (Tooker and De Moraes 2007; Tooker et al. 2008). Moreover, the scenario established by allowing $H$. virescens to

Table 1. Comparison of linolenic, linoleic, 12-oxo-phytodienoic (OPDA), jasmonic, and salicylic acids levels (mean \pm standard error; $\mathrm{ng} \mathrm{g}^{-1} \mathrm{FW}$ ) in undamaged Solidago altissima leaves or those exposed to Heliothis virescens for $72 \mathrm{~h}$

\begin{tabular}{lccccc}
\hline & & & \multicolumn{3}{c}{ Statistics } \\
\cline { 4 - 6 } Compound & $\boldsymbol{H}$. virescens & Control & Student's $\boldsymbol{t}$ & d.f. & $\boldsymbol{P}$ \\
\hline Linolenic & $16,754 \pm 3,387$ & $759 \pm 103$ & 4.7 & $7^{\mathrm{y}}$ & 0.002 \\
Linoleic & $6,231 \pm 1,011$ & $1,527 \pm 233$ & 4.5 & $8^{\mathrm{y}}$ & 0.002 \\
OPDA & $246 \pm 106$ & $0 \pm 0$ & $\mathrm{NA}^{\mathrm{z}}$ & $\mathrm{NA}^{\mathrm{z}}$ & $\mathrm{NA}^{\mathrm{z}}$ \\
Jasmonic & $784 \pm 118$ & $141 \pm 42$ & 5.1 & $9^{\mathrm{y}}$ & 0.0007 \\
Salicylic & $778 \pm 252$ & $691 \pm 200$ & 0.27 & 14 & 0.79 \\
\hline
\end{tabular}

${ }^{\text {y }}$ Student's $t$ test for unequal variances.

${ }^{\mathrm{z}}$ Statistics not appropriate. feed upon $S$. altissima should not be too different from a host plant reacting to a generalist caterpillar exploring its food options when preferred host plants are not present.

$H$. virescens caterpillars severely damaged growth chambergrown S. altissima after $72 \mathrm{~h}$ of exposure. Analyses of damaged leaves from these plants revealed that $H$. virescens significantly elevated levels of LNA, LA, OPDA, and JA but not SA (Table 1). Also, we detected significant positive linear relationships between LNA and JA, LA and JA, OPDA and JA, OPDA and LNA, and OPDA and LA (Table 2).

\section{Levels of LNA, LA, OPDA, JA, and SA \\ in G. gallaesolidaginis galls.}

Gall insects typically induce spatially and temporally complex changes in the tissues that constitute their galls, causing interior gall tissue to differentiate into specialized tissue on which the insect feeds, whereas exterior tissues remain similar to those of ungalled stems but can have elevated levels of plant secondary metabolites (Abrahamson et al. 1991; Allison and Schultz 2005; Beck 1953; Hartley 1998; Nyman and Julkunen-Tiitto 2000). Therefore, we collected G. gallaesolidaginis galls and ungalled control stems of $S$. altissima from the field weekly during the growing season and dissected galls and ungalled stems on dry ice, collecting samples of the tissue lining both the interior and exterior of galls and ungalled stems (details on the cell layers collected are provided below). Field collections were necessary because of the large numbers of galls needed for our analyses. Free carboxylic acids in the tissue samples were extracted, methylated, and analyzed by coupled gas chromatography-mass spectrometry (GC-MS). For statistical analysis, we grouped galls and ungalled stems into size classes based on diameter because we could not be certain of the ages of these fieldcollected specimens and galls of similar size are often of similar age (further justification of size classes is provided below).

Levels of LNA and LA from interior and exterior tissue of stems galled by $G$. gallaesolidaginis varied significantly across size classes (Table 3). For both fatty acids, main effects of tissue (interior versus exterior) and size class were both statistically significant (Table 3; Fig. 1A and B). Further, both LNA and LA yielded significant tissue-class interactions indicating that, within some diameter classes, there were significant differences between amounts of LNA and LA in interior and exterior gall tissue (Table 3; Fig. 1A and B). Specifically, classes $\mathrm{B}$ and $\mathrm{C}$ both had interior levels of LNA and LA that were significantly higher than exterior tissue (Fig. 1A and B) indicating that feeding by $G$. gallaesolidaginis increased LNA and LA content on the inside of galls. Moreover, the relatively low LNA and LA content on the exterior of galls indicates that the influence of $G$. gallaesolidaginis was localized and did not extend to adjacent tissue (Fig. 1A and B).

In contrast to the two fatty acids, levels of JA and its immediate precursor OPDA were statistically similar across diameter

Table 2. Linear regression results for amounts of linolenic, linoleic, 12-oxo-phytodienoic (OPDA), jasmonic, and salicylic acids in Solidago altissima leaves exposed to Heliothis virescens for $72 \mathrm{~h}^{\mathrm{z}}$

Compound

\begin{tabular}{|c|c|c|c|c|c|c|c|c|}
\hline \multirow[b]{3}{*}{ Compound } & \multicolumn{4}{|c|}{ OPDA } & \multicolumn{4}{|c|}{ Jasmonic } \\
\hline & \multicolumn{3}{|c|}{ Statistics } & \multirow[b]{2}{*}{ Best fit regression line } & \multicolumn{3}{|c|}{ Statistics } & \multirow[b]{2}{*}{ Best fit regression lint } \\
\hline & $R^{2}$ & $F_{1,15}$ & $P$ & & $R^{2}$ & $F_{1,15}$ & $P$ & \\
\hline Linolenic & 0.67 & 29.1 & 0.0001 & $Y=0.01 X+23.1$ & 0.32 & 6.5 & 0.024 & $Y=0.02 X+271$ \\
\hline Linoleic & 0.59 & 20.1 & 0.0005 & $Y=0.04 X-15.3$ & 0.41 & 9.6 & 0.008 & $Y=0.08 X+139$ \\
\hline OPDA & $\ldots$ & $\ldots$ & $\ldots$ & $\ldots$ & 0.56 & 17.5 & 0.001 & $Y=2.1 X+205$ \\
\hline Jasmonic & 0.56 & 17.5 & 0.001 & $Y=2.1 X+205$ & $\ldots$ & $\ldots$ & $\ldots$ & $\ldots$ \\
\hline Salicylic & NS & $\ldots$ & $\ldots$ & $\ldots$ & NS & $\ldots$ & $\ldots$ & $\ldots$ \\
\hline
\end{tabular}

${ }^{\mathrm{z}} \mathrm{NS}=$ not significant. 
classes and between the interior and exterior of galls, indicating that increases in LNA and LA did not result in the production of more OPDA or JA through the octadecanoid pathway (Table 3; Fig. 2A and B). SA levels varied significantly across size classes and generally decreased as gall diameter increased (Table 3; Fig. 3A). Tissue identity, however, did not significantly influence SA levels, indicating that $G$. gallaesolidaginis caterpillars did not increase SA production inside galls (Table 3; Fig. 3A). The tissue-class interaction marginally affected SA levels but this difference was driven by size-class rather than tissue-type differences, consistent with the observation that larger galls had lower SA content (Table 3 ).

Multivariate analysis of galled stems revealed that LNA was significantly and positively associated with LA $\left(R^{2}=0.85, P<\right.$ 0.0001 ) but, unlike our results with $H$. virescens, neither fatty acid was significantly associated with OPDA or JA $\left(R^{2}<0.12\right.$,
$P>0.20$ ), suggesting that $G$. gallaesolidaginis feeding does not induce a typical octadecanoid cascade. Moreover, the analysis showed significant main effects of tissue, class, and their interaction (Wilks Lambda for tissue: $F_{1,112}=7.0, P<0.0001$; class: $F_{12,297}=2.4, P=0.006$; tissue-class interaction: $F_{12,297}=2.2, P=$ 0.01 ), supporting our univariate analyses and indicating that $G$. gallaesolidaginis strongly influenced the content of their galls.

\section{Levels of LNA, LA, OPDA, JA, and SA in ungalled stems of $S$. altissima.}

Levels of LNA and LA also varied statistically in ungalled control stems, with both fatty acids being significantly influenced by the main effects of tissue and class (Table 3; Fig. 1C and D). In particular, exterior tissue in ungalled stems had significantly greater LNA content than interior tissues though this difference is not obvious from the figure (Fig. 1C; 8,343 \pm 698

Table 3. Results of analysis of variance (ANOVA) on linolenic, linoleic, 12-oxo-phytodienoic (OPDA), jasmonic, and salicylic acids measured in Gnorimoschema gallaesolidaginis galls and ungalled control stems ${ }^{\mathrm{Z}}$

\begin{tabular}{|c|c|c|c|c|c|c|c|c|}
\hline \multirow[b]{3}{*}{ Compound } & \multirow{2}{*}{\multicolumn{2}{|c|}{ Overall ANOVA }} & \multicolumn{6}{|c|}{ Main effects } \\
\hline & & & \multicolumn{2}{|c|}{ Tissue } & \multicolumn{2}{|c|}{ Size class } & \multicolumn{2}{|c|}{ Interaction } \\
\hline & $\begin{array}{c}\text { Gall } \\
F_{7,122}(P) \\
\end{array}$ & $\begin{array}{l}\text { Ungalled } \\
F_{7,118}(P) \\
\end{array}$ & $\begin{array}{c}\text { Gall } \\
F_{1,122}(P) \\
\end{array}$ & $\begin{array}{l}\text { Ungalled } \\
F_{1,118}(P) \\
\end{array}$ & $\begin{array}{c}\text { Gall } \\
F_{3,122}(P) \\
\end{array}$ & $\begin{array}{l}\text { Ungalled } \\
F_{3,118}(P) \\
\end{array}$ & $\begin{array}{c}\text { Gall } \\
F_{3,122}(P) \\
\end{array}$ & $\begin{array}{l}\text { Ungalled } \\
F_{3,118}(P) \\
\end{array}$ \\
\hline Linolenic & $8.7(<0.0001)$ & $3.1(0.005)$ & $24.5(<0.0001)$ & $4.1(0.05)$ & $7.2(0.0002)$ & $4.6(0.004)$ & $4.5(0.005)$ & $0.4(0.74)$ \\
\hline Linoleic & $7.9(<0.0001)$ & $5.3(<0.0001)$ & $24.0(<0.0001)$ & $4.6(0.03)$ & 6.7 (0.0003) & $10.2(<0.0001)$ & $3.4(0.02)$ & $1.1(0.37)$ \\
\hline OPDA & $1.7(0.11)$ & $2.3(0.03)$ & $\ldots$ & $4.5(0.04)$ & $\ldots$ & $2.8(0.04)$ & $\ldots$ & $0.4(0.80)$ \\
\hline Jasmonic & $1.7(0.12)$ & $1.0(0.42)$ & 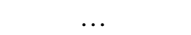 & & $\ldots$ & & . & \\
\hline Salicylic & $6.3(<0.0001)$ & $7.0(<0.0001)$ & $0.4(0.52)$ & $29.5(<0.0001)$ & $11.9(<0.0001)$ & $1.5(0.22)$ & $2.3(0.08)$ & $3.0(0.03)$ \\
\hline
\end{tabular}

${ }^{\mathrm{z}}$ Statistics performed on log-transformed data.
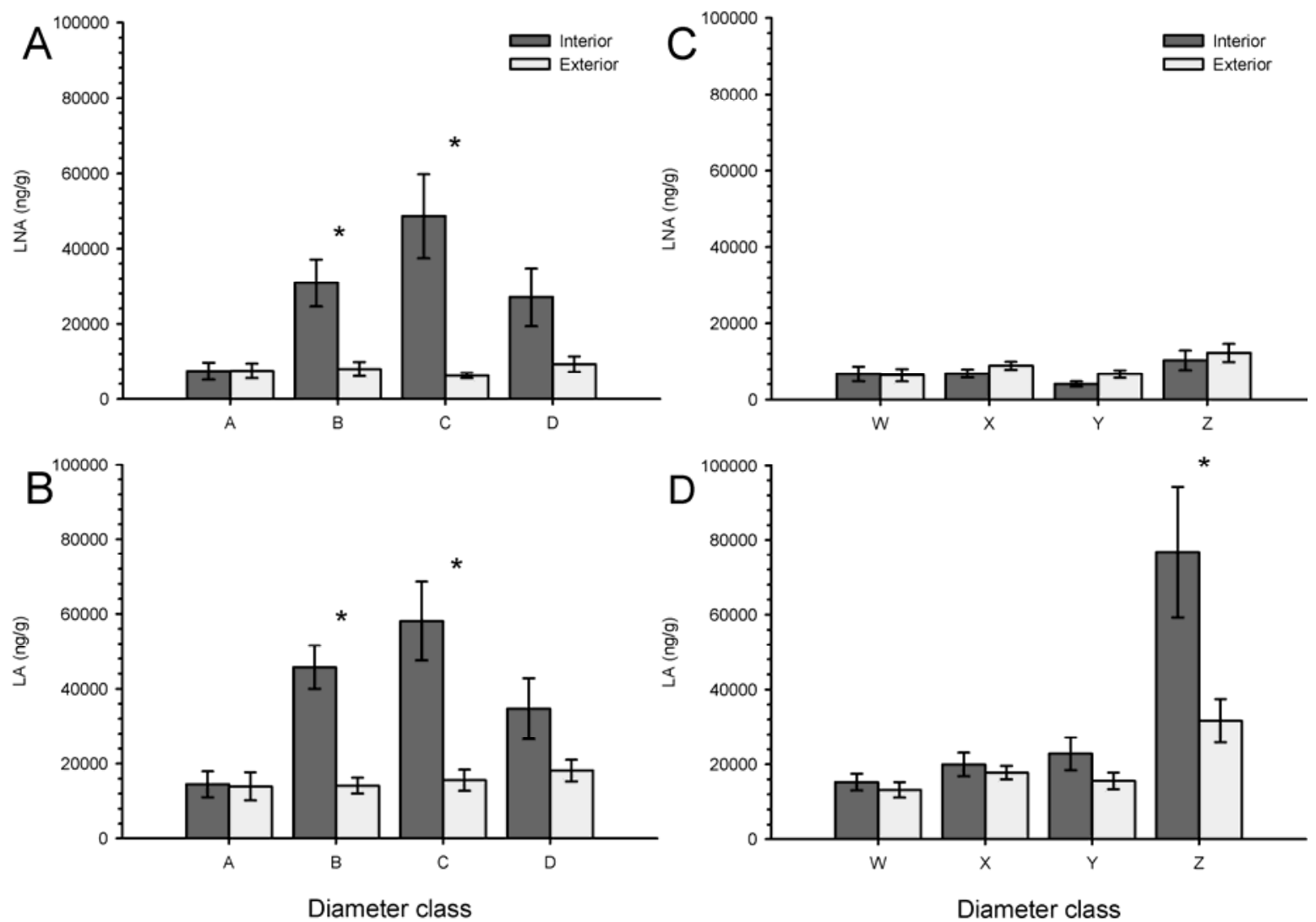

Fig. 1. Levels (mean \pm standard error) of linolenic (LNA) and linoleic (LA) acids in interior and exterior tissue from A and $\mathbf{B}$, Gnorimoschema gallaesolidaginis galls and $\mathbf{C}$ and $\mathbf{D}$, ungalled control stems of Solidago altissima. Galls were organized into four different diameter-size classes: class $\mathrm{A}=2.75$ to 6.69 $\mathrm{mm}(n=15)$, class $\mathrm{B}=6.69$ to $10.63(n=9)$, class $\mathrm{C}=10.63$ to $14.57(n=19)$, and class $\mathrm{D}=14.57$ to $18.50(n=19)$, as were ungalled stems: $\mathrm{W}=1.75$ to $2.69 \mathrm{~mm}(n=10), \mathrm{X}=2.69$ to $3.63(n=25), \mathrm{Y}=3.63$ to $4.57(n=17)$, and $\mathrm{Z}=4.57$ to $5.50(n=8)$. Asterisks indicate significant differences between acid levels on the interior and exterior of galls or ungalled stems (Tukey's highly significant difference, $P<0.05$; data are shown untransformed). 
and $6,486 \pm 700 \mathrm{ng} \mathrm{g}^{-1}$, exterior and interior tissues, respectively; Tukey's highly significant difference [HSD], $P=0.05$ ). In contrast, LA showed the opposite pattern, being significantly higher in interior tissue (Fig 1D; Tukey's HSD, $P=0.03$ ). Linoleate was also highest in the largest ungalled size class relative to the three smaller classes (Fig 1D; Tukey's HSD, $P<$ $0.0001)$. For LNA, the largest size class (Z) contained significantly more LNA than just the second-largest size class (Y) (Fig. 1C; Tukey's HSD, $P=0.003$ ). Neither LNA nor LA yielded significant interaction terms, indicating that interior and exterior tissues from ungalled stems were largely similar in LNA and LA content across size classes (Table 3; Fig. 1C and D), contrary to our findings for galled tissue. OPDA levels in ungalled stems varied significantly across size classes and tissues; however, the interaction term was insignificant, indicating that the interior and exterior of stems were similar for each of the size classes (Table 3; Fig. 2C). Levels of JA in control stems also were statistically similar between interior and
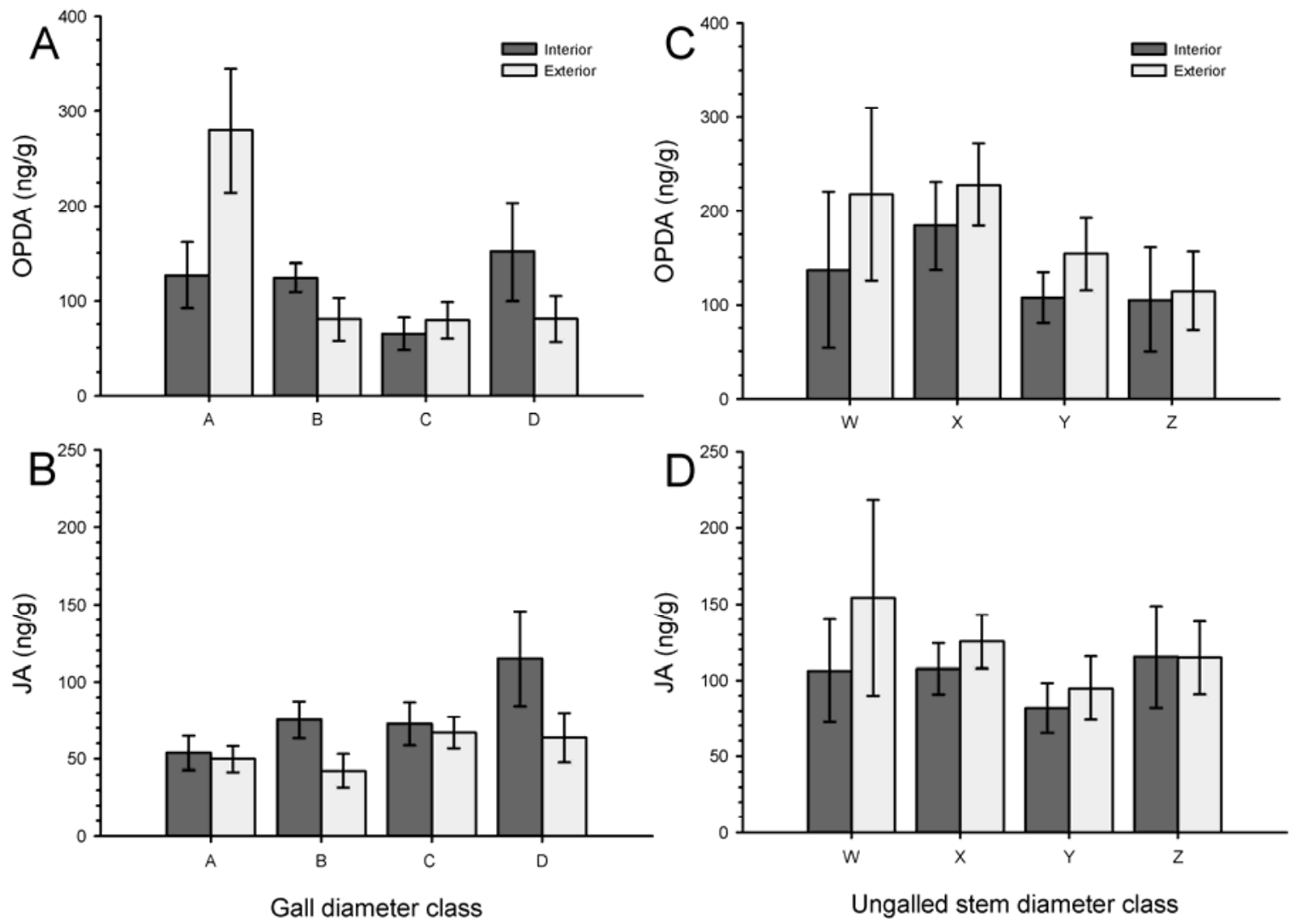

Fig. 2. Levels (mean \pm standard error) of 12-oxo-phytodienoic (OPDA) and jasmonic (JA) acids in interior and exterior tissue from $\mathbf{A}$ and $\mathbf{B}$, Gnorimoschema gallaesolidaginis galls and $\mathbf{C}$ and $\mathbf{D}$, ungalled control stems of Solidago altissima. Galls and ungalled stems were each organized into four different diameter-size classes: class $\mathrm{A}=2.75$ to $6.69 \mathrm{~mm}(n=15)$, class $\mathrm{B}=6.69$ to $10.63(n=9)$, class $\mathrm{C}=10.63$ to $14.57(n=19)$, and class $\mathrm{D}=14.57$ to $18.50(n=19)$, as were ungalled stems: $\mathrm{W}=1.75$ to $2.69 \mathrm{~mm}(n=10), \mathrm{X}=2.69$ to $3.63(n=25), \mathrm{Y}=3.63$ to $4.57(n=17)$, and $\mathrm{Z}=4.57$ to $5.50(n=8)$. No statistical differences were found between interior and exterior tissues within size classes for either these two compounds (Tukey's highly significant difference, $P>0.05$; data are shown untransformed).

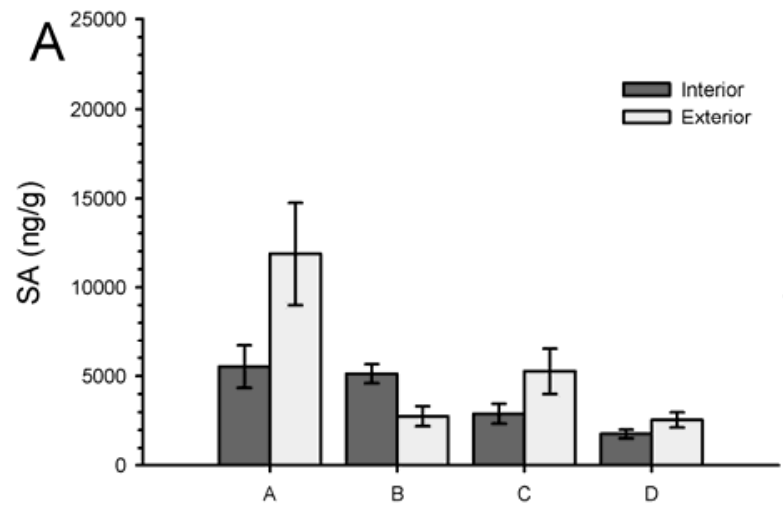

Gall diameter class

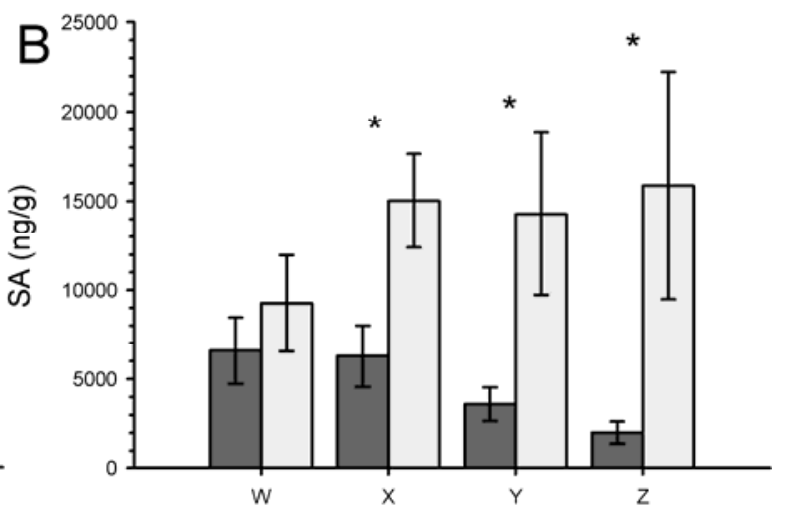

Ungalled stem diameter class

Fig. 3. Levels (mean \pm standard error) of salicylic acid (SA) in interior and exterior tissue from A, Gnorimoschema gallaesolidaginis galls and B, ungalled control stems of Solidago altissima. Galls and ungalled stems were each organized into four different diameter-size classes: class A $=2.75$ to 6.69 mm $(n=$ $15)$, class $\mathrm{B}=6.69$ to $10.63(n=9)$, class $\mathrm{C}=10.63$ to $14.57(n=19)$, and class $\mathrm{D}=14.57$ to $18.50(n=19)$, as were ungalled stems: $\mathrm{W}=1.75$ to 2.69 mm $(n=10), \mathrm{X}=2.69$ to $3.63(n=25), \mathrm{Y}=3.63$ to $4.57(n=17)$, and $\mathrm{Z}=4.57$ to $5.50(n=8)$. Asterisks indicate significant differences between acid levels on the interior and exterior of galls or ungalled stems (Tukey's highly significant difference, $P<0.05$; data are shown untransformed). 
exterior tissues and across size classes but SA amounts varied significantly (Table 3; Figs. 2D and 3B): for the three largest size classes, tissue from the exterior of ungalled stems had higher SA amounts than interior tissue (Fig. 3B), differences not evident in galled stems.

Multivariate analysis of ungalled stems indicated that LA was significantly and positively associated with LNA $\left(R^{2}=\right.$ $0.71, P<0.0001)$ and JA $\left(R^{2}=0.21, P<0.03\right)$ but was negatively associated with OPDA $\left(R^{2}=-0.23, P=0.02\right)$. OPDA and LNA were also negatively associated $\left(R^{2}=-0.27, P=\right.$ $0.004)$, whereas LNA and JA $\left(R^{2}=-0.04, P=0.68\right)$ and OPDA and JA $\left(R^{2}=0.16, P=0.10\right)$ were not statistically related. The multivariate analysis also revealed significant effects of tissue and class (Wilks Lambda for tissue: $F_{4,108}=11.3, P<0.0001$; class: $\left.F_{12,286}=4.5, P<0.0001\right)$ but not of their interaction (Wilks Lambda for tissue-class interaction: $F_{12,286}=1.1, P=$ 0.41 ), indicating that interior and exterior tissues were largely similar within size classes, contrasting with our findings for galled stems. These results support our univariate analyses and, together with the multivariate analyses of galled tissues, support the notion that G. gallaesolidaginis altered LNA and LA content of galls relative to ungalled stems.

\section{Direct comparison of galls and ungalled stems.}

When we ignored size classes and directly compared tissue from galled and ungalled stems, we found that levels of LNA, LA, JA, and SA varied significantly, whereas OPDA did not (Table 4). Linolenate levels were significantly influenced by both gall status (i.e., galled versus ungalled stems) and tissue, with the interior of galled stems having the highest values (Table 4). Linoleate was also highest on the interior of galls but levels were not influenced significantly by gall status because the interior of ungalled stems had relatively high linoleate content (Table 4). In contrast, JA levels were not influenced significantly by tissue identity (interior versus exterior) but were influenced by gall status and by the gall-tissue interaction (Table 4). Differences for the latter two effects were driven by higher JA levels in ungalled stems, particularly in exterior tissue (Table 4). SA levels were significantly influenced by all three effects but SA values were highest in exterior tissues of ungalled stems (Table 4).

When we collected galls and ungalled stems in the field, we included any attached leaves to determine whether any changes induced in galls extended to adjacent leaves. Levels of LNA, LA, OPDA, and JA in leaves attached to G. gallaesolidaginis galls were statistically similar to those of leaves attached to ungalled control stems (overall analysis of variance [ANOVA]: LNA: $F_{1,122}=0.44, P=0.51$; LA: $F_{1,122}=0.1, P=0.81$; OPDA: $F_{1,122}=0.1, P=0.71$; JA: $F_{1,122}=0.2, P=0.69$ ), further suggesting that the influence of $G$. gallaesolidaginis is localized to interior tissues. Leaves attached to galls, however, had marginally higher levels of SA relative to leaves from ungalled control stems $\left(3,906 \pm 652\right.$ and 2,506 $\pm 454 \mathrm{ng} \mathrm{g}^{-1} \mathrm{FW}$, respec- tively [mean \pm standard error]; ANOVA $F_{1,122}=3.7, P=0.06$ ), indicating that perhaps galling influences can extend beyond the interior of the gall for some compounds.

\section{DISCUSSION}

Feeding by $H$. virescens caterpillars strongly increased levels of free LNA and LA in damaged leaves relative to those from control plants. Because leaves are typically well defended, for the purposes of this article this response can be considered "typical" of how S. altissima can react to generalist caterpillar feeding, and deviations from this standard may be notable. The $H$. virescens-induced levels of LNA and LA in leaves of lab-grown plants were in the range of LNA and LA amounts measured in leaves of our field-collected plants, indicating that our field plants had suffered herbivory or some other stress that elevated their LNA and LA levels well above those of our undamaged, lab-grown plants. Unexpectedly, $G$. gallaesolidaginis caterpillars more strongly influenced free LNA and LA levels in stems than $H$. virescens did in leaves; these gall-inducing caterpillars greatly increased concentrations of LNA and LA on the interior of galls where larvae feed but not in gall exteriors or attached leaves. Importantly, LNA and LA levels in gall interiors were more than three and nine times greater, respectively, than amounts detected in $H$. virescens-damaged leaves from lab-grown plants. These results were unexpected because leaves appear to be better defended than stems (Karban and Baldwin 1997) and one would expect a stronger defensive response in better-defended tissue. Moreover, leaves tend to be rich in chloroplasts whereas gall interiors are white, seemingly lacking photosynthetic structures; LNA, in particular, is typically strongly associated with chloroplasts and tends to be less common in weakly photosynthetic or nonphotosynthetic shoot and roots (del Rio-Celestino et al. 2008; Harwood and Russell 1983). In other plant species, green leaves with limited access to light or even white tissues have been shown to have less LNA than leaves with full access to light or green tissues (Burkey et al. 1997; Leech et al. 1973). Because the white interior of G. gallaesolidaginis galls are not exposed to sunlight and show no obvious evidence of chloroplasts, our results suggest that $G$. gallaesolidaginis increases LNA concentrations in a somewhat atypical location.

This finding is intriguing because LNA and LA have been found to be essential, diet-acquired fatty acids for lepidopteran species, necessary for larval and pupal development and for adult emergence (Bracken 1982; De Moraes and Mescher 2004; Vanderzant 1968). Some insect species can synthesize LNA and LA de novo to satisfy their need for these compounds (Buckner and Hagen 2003; de Renobales et al. 1987) but $G$. gallaesolidaginis may have evolved a different tactic, inducing $S$. altissima to produce in nonphotosynthetic tissue greater amounts of free LNA and LA than would be available to other insect species. It should be noted that establishing the

Table 4. Comparison without size classes of linolenic, linoleic, 12-oxo-phytodienoic (OPDA), jasmonic, and salicylic acids levels (mean \pm standard error; $\mathrm{ng} \mathrm{g}^{-1} \mathrm{FW}$ ) in tissue from G. gallaesolidaginis galls and ungalled control stems ${ }^{\mathrm{y}}$

\begin{tabular}{|c|c|c|c|c|c|c|c|c|}
\hline \multirow[b]{3}{*}{ Compound } & \multirow{2}{*}{\multicolumn{2}{|c|}{ Galls }} & \multirow{2}{*}{\multicolumn{2}{|c|}{ Ungalled stem }} & \multicolumn{4}{|c|}{ ANOVA $^{z}$} \\
\hline & & & & & \multirow{2}{*}{$\begin{array}{c}F_{3,243}(P) \\
\text { Overall }\end{array}$} & \multicolumn{3}{|c|}{ Effects, $F_{1,243}(P)$} \\
\hline & Interior & Exterior & Interior & Exterior & & Gall & Tissue & Interaction \\
\hline Linolenic & $29,449 \pm 4,630 \mathrm{a}$ & $7,697 \pm 854 b$ & $6,468 \pm 689 b$ & $8,389 \pm 687 b$ & $15.8(0.0001)$ & $13.6(0.003)$ & $5.6(0.02)$ & $27.6(<0.0001)$ \\
\hline Linoleic & $38,562 \pm 4,650 \mathrm{a}$ & $15,720 \pm 1,540 \mathrm{c}$ & $27,551 \pm 3,748 \mathrm{ab}$ & $18,455 \pm 1,430 \mathrm{bc}$ & $8.7(0.0001)$ & $0.02(0.88)$ & $20.1(<0.0001)$ & $5.9(0.02)$ \\
\hline OPDA & $115 \pm 19$ & $129 \pm 22$ & $144 \pm 26$ & $190 \pm 26$ & $1.9(0.13)$ & & & \\
\hline Jasmonic & $81.5 \pm 11.0 \mathrm{ab}$ & $58.2 \pm 6.3 \mathrm{~b}$ & $100.5 \pm 10.7 \mathrm{ab}$ & $118.6 \pm 13.6 \mathrm{a}$ & $3.3(0.021)$ & $4.8(0.03)$ & $0.20(0.66)$ & $5.0(0.03)$ \\
\hline Salicylic & $3,514 \pm 393 b$ & $5.723 \pm 933 b$ & $4.948 \pm 833 b$ & $13,948 \pm 1,906 \mathrm{a}$ & $19.7(0.0001)$ & $24.1(<0.0001$ & $24.7(<0.0001)$ & $10.8(0.001)$ \\
\hline
\end{tabular}

${ }^{\mathrm{y}}$ Within rows, values marked with different letters are significantly different (Tukey's highly significant difference, $P<0.05$ ).

${ }^{\mathrm{z}}$ Statistics performed on log-transformed data. 
true nutritional importance of LNA and LA for G. gallaesolidaginis will be a challenge because we have not been able to rear G. gallaesolidaginis caterpillars on an artificial diet and Solidago mutants are not available.

Even though we measured only free fatty acids, our findings that G. gallaesolidaginis caterpillars increase fatty acids known to be nutritionally beneficial supports the "nutrition hypothesis" for the adaptive significance of galls, which states that galls evolved to provide insects with a better food source than would be otherwise available (Price et al. 1987; Stone and Schönrogge 2003). Other gall insect species can influence fatty acid content of their galls but these previous studies either did not focus on specific fatty acids or analyzed whole-gall extracts (Bayer 1991; Harper et al. 2004; Motta et al. 2005). Our results illustrate that at least one gall-inducing species increases fatty acid composition specifically in the tissues on which they feed.

Although increased LNA and LA levels should improve the nutritive quality of plant tissues, elevated levels of these fatty acids may be problematic for insect herbivores because LNA and LA themselves, in addition to their metabolites, including OPDA, can induce plant defense responses (Farmer and Ryan 1992). In some plant species, the enzymes that drive OPDA and JA synthesis appear to be present at low levels even in undamaged tissue; therefore, excess LNA leads directly to greater JA synthesis (Farmer and Ryan 1992). The role of LA in JA production is unclear, even though LA can be converted by plants to LNA (Farmer and Ryan 1992; Karban and Baldwin 1997). It is not apparent whether our results with S. altissima support a similar "constitutive model" of the octadecanoid pathway. We detected significant positive relationships among LNA, LA, OPDA, and JA following $72 \mathrm{~h}$ of $H$. virescens feeding, but this amount of time would appear sufficient to synthesize new octadecanoid-related enzymes. Therefore, shorter bouts of herbivory that would draw on standing stocks of enzymes would be necessary to assess the potential constitutive nature of the octadecanoid pathway in S. altissima. Nevertheless, whereas we detected strong increases in OPDA and JA associated with $H$. virescen-induced increases in LNA and LA, we did not detect an increase in OPDA or JA levels on the interior of G. gallaesolidaginis galls despite very high levels of LNA and LA (Fig. 2A and B). Moreover, G. gallaesolidaginis feeding on gall interiors did not result in any significant relationships between LNA or LA and OPDA or JA as $H$. virescens feeding did. This finding suggests that, while inducing increases in LNA and LA, G. gallaesolidaginis may somehow fail to trigger octadecanoid-mediated defense responses. Further, G. gallaesolidaginis feeding also did not significantly increase volatile emissions, including six-carbon green-leaf volatiles (Tooker et al. 2008), which are additional degradation products of LNA that can themselves function as indirect plant defenses (Engelberth et al. 2004).

As indicated above, we found a significant positive relationship between levels of LNA and JA following $72 \mathrm{~h}$ of damage by $H$. virescens caterpillars but did not detect a similar relationship following herbivory by $G$. gallaesolidaginis caterpillars. It might seem unreasonable to hypothesize that JA levels would be elevated after several weeks of G. gallaesolidaginis feeding because of the well-documented increase and subsequent decline of JA that occurs shortly after feeding begins (the so-called "JA burst") (Ziegler et al. 2001). However, attention focused on this burst may be in part an artifact of experimental designs that measure JA levels for short periods of time (typically $\leq 24 \mathrm{~h}$ ) after brief bouts of herbivory. As we report here, S. altissima maintains significantly elevated JA levels well beyond the JA burst that occurs within the first hour following $H$. virescens damage. Other plant species also appear to maintain elevated levels of JA during prolonged bouts of herbi- vory spanning several days to a few months (McCloud and Baldwin 1997; Mopper et al. 2004). Therefore, it is notable that continued feeding by G. gallaesolidaginis did not increase JA levels in our study, particularly when LNA and LA levels were so high. Unfortunately, longer lengths of exposure of $S$. altissima to $H$. virescens and many other exophytic caterpillar species would be impractical because whole leaves would be consumed, leaving no tissue to assay.

At least one caterpillar species has adapted to feed on fruit lacking LNA and, consequently, avoids some of the herbivoreinduced indirect defenses of its host plant (De Moraes and Mescher 2004). G. gallaesolidaginis, however, may have evolved a different tactic that is not sensitive to increases in LNA or LA in interior gall tissues. It remains possible that the observed build-up of LNA and LA in interior gall tissue could be a nonadaptive byproduct of galling, part of an active response to galling mounted by the plant or a generalized plant response to herbivory. The strong increase in LNA and LA following $H$. virescens damage supports this latter possibility; however, $H$. virescens-induced levels did not approach those found on the interiors of galls, suggesting that G. gallaesolidaginis has a unique influence on its host-plant species. Given the manipulative skills of gall-insect species, it is tempting to speculate that G. gallaesolidaginis manipulates S. altissima to increase the nutritional value of its host plant, but further research will be necessary to confirm this. Further research will also be necessary to determine whether the LNA and LA increases are of primary nutritional importance for the galling larvae (Bracken 1982; Vanderzant 1968) or play a secondary role such as enhancing survival of the overwintering eggs of G. gallaesolidaginis (Bennett et al. 1997).

Few caterpillar species have been found to induce SA production (Bi et al. 1997; Walling 2000) and, accordingly, neither $H$. virescens nor $G$. gallaesolidaginis increased SA levels of $S$. altissima. This finding for $G$. gallaesolidaginis contrasts with results for another gall insect species which was shown to trigger SA production (Ollerstam and Larsson 2003). In some systems, increases in SA levels have been shown to negatively influence JA-related defenses (Felton et al. 1999) but the lack of SA induction would appear to discount this possibility for G. gallaesolidaginis.

Despite not altering SA on gall interiors, G. gallaesolidaginis did significantly change SA concentrations in galled stems relative to ungalled stems (Fig. 1C and F). It is unclear what G. gallaesolidaginis might gain by decreasing SA content in gall exteriors, but the strong consistent differences we detected may suggest that there is some advantage for $G$. gallaesolidaginis to minimize SA content in some gall tissue, even if it is not meant to be consumed by the gall inducer. Further, it seems likely that the decreased SA content of gall exteriors, or even slightly elevated levels in leaves attached to galls, could have ecological repercussions, potentially altering interactions of gall-infested S. altissima with other arthropods or plant pathogens. In fact, some members of the S. altissima insect community can be strongly associated with other gall-insect species (Maddox and Root 1990) but similar relationships do not appear to have been investigated for G. gallaesolidaginis.

In summary, G. gallaesolidaginis induced strong changes in free LNA and LA levels inside its galls beyond those induced by a generalist caterpillar species. Moreover, the increased levels of LNA are notable because they are occurring in nonphotosynthetic tissue and LNA is often more strongly associated with chloroplasts. Tissue-specific, herbivore-induced increases of LNA and LA or other essential fatty acids (free or membrane bound) do not appear to have been reported previously but could enhance larval nutrition, supporting the hypothesis that nutritional benefits may have favored evolution of the gall- 
inducing habit. Despite elevated LNA and LA content, G. gallaesolidaginis did not induce greater OPDA or JA production, as $H$. virescens did, suggesting that the gall-inducing caterpillar species somehow failed to trigger a typical octadecanoid cascade. This inference is consistent with previous work showing that this gall-insect species does not increase volatile emissions of its host plant. Avoiding JA production could benefit gall-inducing species like $G$. gallaesolidaginis by decreasing their susceptibility to plant defenses, but it also may aid gall formation because JA can be a powerful growth regulator whose presence would seem to hinder gall growth (Tooker and De Moraes 2008). G. gallaesolidaginis also failed to elevate SA levels on gall interiors; therefore, the antagonistic influence of SA does not appear to have been involved in suppressing JA production. Further research is in progress to determine how this gall-inducing caterpillar species achieves these apparent host-plant manipulations.

\section{MATERIALS AND METHODS}

\section{Plant and insect samples.}

We collected $G$. gallaesolidaginis-infested ramets of $S$. altissima from a local old field (Centre County, PA, U.S.A.; $40^{\circ} 53^{\prime} 17^{\prime \prime} \mathrm{N}, 77^{\circ} 46^{\prime} 29^{\prime \prime} \mathrm{W}$ ), selecting ramets with little other herbivore damage and no other galls ( $S$. altissima is host to at least 15 gall-inducing species) (Felt 1940; Gagné 1989), and immediately froze samples in liquid nitrogen. At the same time, we collected samples from adjacent undamaged ramets of approximately the same size. S. altissima occurs in clumped patches because the species is strongly clonal, spreading via rhizomes; therefore, it is likely that our control samples were genetically identical to galled samples. Moreover, using adjacent control stems is preferable to using ungalled sections of galled stems as controls because gall-inducing insects can have dramatic ramet-wide influences over plant morphology and physiology and these ramet-level influences are stronger than potential genet-level influences over adjacent stems (Abrahamson and Weis 1997). These control samples were taken from the same height as the adjacent gall and were approximately $5 \mathrm{~cm}$ long. Our collections began in May 2006, when distinctive plant damage caused by the neonates was evident (Miller 2000). We collected galls weekly during active gall growth, with our eighth and final collection occurring in the first week of August when all of the galls collected had exit holes sealed with bungs, indicating that larvae were approaching pupation (Miller 2000).

We dissected galls and ungalled stems on dry ice, collecting samples of the tissue lining both the interior and exterior of galls and ungalled stems (approximately $30 \mathrm{mg}$ of tissue per sample). The tissue layers sampled from the interior of galls were ray and xylem parenchyma whereas exterior tissues comprised cortex and epidermis (Beck 1953). The latter two tissues were also sampled from the exterior of ungalled stems, while pith was sampled from ungalled-stem interiors. We also collected a portion of one apparently undamaged leaf attached to each gall or ungalled stem (approximately $65 \mathrm{mg} / \mathrm{sample}$ ). The gall-inducing caterpillars themselves were not included in any of our samples. Samples were collected directly into FastPrep tubes (Qbiogene, Carlsbad, CA, U.S.A.) containing $1 \mathrm{~g}$ of Zirmil beads $(1.1 \mathrm{~mm}$; Saint-Gobain ZirPro, Mountainside, NJ, U.S.A.) and frozen at $-80^{\circ} \mathrm{C}$ until processing (discussed below).

For testing the response of S. altissima to a generalist caterpillar, $H$. virescens larvae were reared in an incubator (16 and $8 \mathrm{~h}, 22$ and $20^{\circ} \mathrm{C}$, day and night, respectively; $65 \%$ relative humidity) from eggs on an artificial casein-based diet. Third-instar caterpillars were starved for $24 \mathrm{hr}$ prior to being placed on S. altissima plants and one caterpillar was used per pot.
S. altissima plants were grown from rhizomes collected from a local old field (Centre County, PA). These rhizomes were harvested from plants that had developed G. gallaesolidaginis galls the previous growing season and stored at $4{ }^{\circ} \mathrm{C}$ until use (approximately 16 weeks). We washed rhizomes to remove soil, cut them into 5 -cm lengths, and planted them in shallow trays with peat-based, general-purpose potting soil (Pro-Mix BX; Premier Horticulture Inc., Quakertown, PA, U.S.A.). When the ramets were $10 \mathrm{~cm}$ tall (approximately 2 weeks after planting), we transplanted them into pots $(16 \mathrm{~cm}$ in diameter, $16.5 \mathrm{~cm}$ tall, soil as above).

To confine $H$. virescens larvae on $S$. altissima in the growth chamber, individual plants were isolated in glass cylinders (46.5 $\mathrm{cm}$ tall, $8 \mathrm{~cm}$ in diameter) topped Teflon caps. To prevent condensation inside chambers, filtered air was pushed (2.5 liters $\mathrm{min}^{-1}$ ) into the cylinder through Teflon tubing. The cylinder rested on a two-piece Teflon base, which lay on the rim of the pot and had a hole for the plant stem to pass. To plug the gap between stem and base, we wrapped plant stems in cotton where they passed through the hole. Eight plants were exposed to $H$. virescens and eight control plants were treated similarly but lacked caterpillars. After $72 \mathrm{~h}$ of feeding, damaged and control leaves were collected directly into FastPrep tubes (as above) and frozen at $-80^{\circ} \mathrm{C}$ until processing (discussed below).

\section{Extraction and quantification of phytohormones.}

To extract and detect LNA, LA, OPDA, JA, and SA, we used a method previously described by Schmelz and associates (2003, 2004). Briefly, we derivatized carboxylic acids to methyl esters, which were isolated using vapor phase extraction and analyzed by GC-MS with isobutane chemical ionization using selected-ion monitoring. We quantified amounts of JA using $100 \mathrm{ng}$ of dihydrojasmonic acid; SA using $100 \mathrm{ng}$ of $\left[{ }^{2} \mathrm{H}_{6}\right] \mathrm{SA}$ (CDN Isotopes, Pointe-Claire, Quebec, Canada); and LNA, LA, and OPDA using $100 \mathrm{ng}$ of gamma-linolenic acid (Matreya LLC, Pleasant Gap, PA, U.S.A.). Dihydrojasmonic acid was derived by subjecting methyl dihydrojasmonate (Bedoukian Research Inc., Danbury, CT, U.S.A.) to alkaline hydrolysis. These internal standards were added to our samples prior to processing. We also processed samples without the derivatization agent to verify that the compounds recovered were not themselves present in plant or insect tissues but were derived from the carboxylic acids. To confirm the identity of methyl linolenate (meLNA), methyl linoleate (meLA), methyl OPDA (meOPDA), methyl jasmonate (meJA), and methyl SA (meSA) in our samples, we analyzed extracts by GC-MS with electron ionization, comparing retention times and spectra with that of pure compounds. Retention times and mass spectra of meLNA, meLA, meOPDA, meJA, and meSA recovered from galled, ungalled, and leaf tissue matched the pure standards, confirming the identity of meLNA, meLA, meOPDA, meJA, and meSA in our samples. Moreover, we did not recover methyl esters in the absence of the derivatization agent, verifying that the methyl esters we measured were derivatized from LNA, LA, OPDA, JA, and SA and were not themselves present in samples.

\section{Statistical analyses.}

For most analyses, we separated galled stems by diameter into four size classes: $\mathrm{A}=2.75$ to $6.69 \mathrm{~mm}(n=15) \mathrm{B}=6.69$ to $10.63(n=9), \mathrm{C}=10.63$ to $14.57(n=19)$, and $\mathrm{D}=14.57$ to $18.50(n=19)$. We similarly grouped ungalled stems into four size classes: $\mathrm{W}=1.75$ to $2.69 \mathrm{~mm}(n=10), \mathrm{B}=2.69$ to 3.63 $(n=25), \mathrm{C}=3.63$ to $4.57(n=17)$, and $\mathrm{D}=4.57$ to $5.50(n=$ $8)$. This method was desirable because it allowed use of ANOVA to detect the influence of both size and tissue identity on levels of the various plant compounds. Moreover, this method was 
preferable to the alternative of basing analyses on sample collection dates because plants and animals collected on the same date are always the same age. Finally, distinct size classes were a benefit because stem and gall diameters tend to be well correlated with plant and insect age (Abrahamson and Weis 1997).

For univariate analyses, fatty acid and hormone levels were natural-log transformed to normalize data and stabilize variance. We made comparisons of LNA, LA, OPDA, JA, and SA levels by ANOVA (PROC GLM) with gall, tissue, and their interaction as main effects (SAS Institute 2003). Unique size classes necessitated separate analyses for galled and ungalled stems; however, we compared galls of G. gallaesolidaginis and ungalled stems directly using ANOVA, ignoring size classes and having gall, tissue, and their interaction as main effects. Finally, we used ANOVA to compare levels of compounds in leaves collected from galled and ungalled stems. For all ANOVAs, we confirmed that there were no patterns in the dispersion of residuals that would indicate nonlinear relationships between variables and compared individual means with Tukey's HSD mean separation test (Sokal and Rohlf 1995), which were "protected" (i.e., means-separation tests were contingent on a significant overall $F$ ) (Day and Quinn 1989).

Student's $t$ tests (PROC TTEST) were used to compare levels of LNA, LA, OPDA, JA, and SA in $H$. virescens-damaged leaves and undamaged controls (SAS Institute 2003; Sokal and Rohlf 1995). We tested for linear relationships among LNA, LA, OPDA, JA, and SA from various tissues using regression analysis (PROC REG) (SAS Institute 2003).

Because amounts of LNA, LA, OPDA, and JA were significantly correlated with each other within some treatments, we also subjected the transformed data to a multivariate analysis of variance, using Wilks-Lambda to test for significance of main effects of gall, tissue, and their interaction (MANOVA; PROC GLM) (SAS Institute 2003). The multivariate approach addresses intercorrelations between dependent variables and controls the type I error rate, which can inflate when conducting multiple tests of correlated dependent variables.

\section{ACKNOWLEDGMENTS}

We thank J. Saunders, E. Bogus, C. Wagner, and E. Smeyers for providing research assistance; M. Mescher, C. Frost, and E. Farmer for helpful comments on the manuscript; and the Chamber of Business and Industry of Centre County (PA) for access to their property. The project was supported by the David and Lucile Packard Foundation, the Beckman Foundation, the DuPont Young Investigator grant, the National Science Foundation (NSF CAREER no. 0643966), and the National Research Initiative of the United States Department of Agriculture Cooperative State Research, Education and Extension Service (no. 2002-35302-12375 to C. M. De Moraes and no. 2006-01823 to J. F. Tooker).

\section{LITERATURE CITED}

Abrahamson, W. G., and Weis, A. E. 1987. Nutritional ecology of arthropod gall makers. Pages 238-258 in: Nutritional Ecology of Insects, Mites, Spiders, and Related Invertebrates. F. Slansky, Jr., and J. G. Rodriguez, eds. Wiley \& Sons, New York.

Abrahamson W. G., and Weis A. E. 1997. Evolutionary Ecology across Three Trophic Levels: Goldenrods, Gallmakers, and Natural Enemies. Princeton University Press, Princeton, NJ, U.S.A.

Abrahamson, W. G., McCrea, K. D., Whitwell, A. J., and Vernieri, L. A. 1991. The role of phenolics in goldenrod ball gall resistance and formation. Biochem. Syst. Ecol. 19:615-622.

Allison, S. D., and Schultz, J. C. 2005. Biochemical responses of chestnut oak to a galling cynipid. J. Chem. Ecol. 31:151-166.

Bayer, M. H. 1991. Fatty acid composition of galactolipids and phospholipids in neoplasmatic plant tissues (cecidia) and normal leaf tissue. Physiol. Plant. 81:313-318.

Beck, E. G. 1953. The nature of the stimulus in the Solidago gall induced by the larva of Gnorimoschema gallaesolidaginis. Brookhaven Sym.
Biol. 6:235-251.

Bennett, V. A., Pruitt, N. L., and Lee, R. E. 1997. Seasonal changes in fatty acid composition associated with cold-hardening in third instar larvae of Eurosta solidaginis. J. Comp. Physiol. B 167:249-255.

Bi, J. L., Murphy, J. B., and Felton, G. W. 1997. Does salicylic acid act as a signal in cotton for induced resistance to Helicoverpa zea? J. Chem. Ecol. 23:1805-1818.

Bracken, G. K. 1982. The bertha armyworm, Mamestra configurata (Lepidoptera: Noctuidae). Effects of dietary linolenic acid on pupal syndrome, wing syndrome, survival, and pupal fat composition. Can. Entomol. 114:567-573.

Buckner, J. S., and Hagen, M. M. 2003. Triacylglycerol and phospholipid fatty acids of the silverleaf whitefly: Composition and biosynthesis Arch. Insect. Biochem. 53:66-79.

Burkey, K. O., Wilson, R. F., and Wells, R. 1997. Effects of canopy shade on the lipid composition of soybean leaves. Physiol. Plant. 101:591598.

Conconi, A., Miquel, M., Browse, J. A., and Ryan, C. A. 1996. Intracellular levels of free linolenic and linoleic acids increase in tomatoes leaves in response to wounding. Plant Physiol. 111:797-803.

Creelman, R. A., and Mullet, J. E. 1997. Biosynthesis and action of jasmonates in plants. Annu. Rev. Plant Physiol. 48:355-81.

Cripps, C., Blomquist, G. J., and de Renobales M. 1986. De novo biosynthesis of linoleic acid in insects. Biochim. Biophys. Acta 876:572-580.

Dawkins, R. 1982. The Extended Phenotype. W. H. Freeman \& Co., Oxford.

Day, R. W., and Quinn, G. P. 1989. Comparisons of treatments after an analysis of variance in ecology. Ecol. Monogr. 59:433-463.

del Rio-Celestino, M., Font, R., and de Haro-Bailón, A. 2008. Distribution of fatty acids in edible organs and seed fractions of borage (Borago officinalis L.). J. Sci. Food Agric. 88:248-255.

De Moraes, C. M., and Mescher, M. C. 2004. Biochemical crypsis in the avoidance of natural enemies by an insect herbivore. Proc. Natl. Acad. Sci. U.S.A. 101:8993-8997.

De Moraes, C. M., Lewis, W. J., Pare, P. W., Alborn, H. T., and Tumlinson, J. H. 1998. Herbivore-infested plants selectively attract parasitoids. Nature 393:570-573.

de Renobales, D. M., Cripps, C., Stanley-Samuelson, D. W., Jurenka, R. A., and Blomquist, G. J. 1987. Biosynthesis of linoleic acid in insects. Trends Biochem. Sci. 12:364-366.

Doares, S. H., Narvaez-Vasquez, J., Conconi, A., and Ryan, C. A. 1995. Salicylic acid inhibits synthesis of proteinase-inhibitors in tomato leaves induced by systemin and jasmonic acid. Plant Physiol. 108:17411746

Edelaar, P., Drent, P., and de Goeij, P. 2003. A double test of the parasite manipulation hypothesis in a burrowing bivalve. Oecologia 134:66-71.

Eigenbrode, S. D., Ding, H., Shiel, P., and Berger, P. H. 2002. Volatiles from potato plants infected with potato leafroll virus attract and arrest the virus vector, Myzus persicae (Homoptera: Aphididae). Proc. Roy. Soc. B Biol. Sci. 269:455-460.

Engelberth, J., Alborn, H. T., Schmelz, E. A., and Tumlinson, J. H. 2004. Airborne signals prime plants against insect herbivore attack. Proc. Natl. Acad. Sci. U.S.A. 101:1781-1785.

Farmer, E. E., and Ryan, C. A. 1992. Octadecanoid precursors of jasmonic acid activate the synthesis of wound-inducible proteinase inhibitors. Plant Cell 4:129-134.

Felt, E. P. 1940. Plant Galls and Gall Makers. Comstock Publishing, Ithaca, NY, U.S.A.

Felton, G. W., Korth, K. L., Bi. J. L., Wesley, S. V., Huhman, D. V., Mathews, M. C., Murphy, J. B., Lamb, C., and Dixon, R. A. 1999. Inverse relationship between systemic resistance of plants to microorganisms and to insect herbivory. Curr. Biol. 9:317-320.

Gagné, R. J. 1989. The Plant-Feeding Gall Midges of North America. Comstock Publishing, Ithaca, NY, U.S.A.

Harper, L. J., Schönrogge, K., Lim, K. Y., Francis, P., and Lichtenstein, C. P. 2004. Cynipid galls: Insect-induced modifications of plant development create novel plant organs. Plant Cell Environ. 27:327-335.

Hartley, S. E. 1998. The chemical composition of plant galls: Are levels of nutrients and secondary compounds controlled by the gall former? Oecologia 113:492-501.

Harwood, J. L., and Russell N. J. 1983. Lipids in Plants and Microbes. George Allen \& Unwin, London.

Hopke, J., Donath, J., Blechert, S., and Boland, W. 1994. Herbivore-induced volatiles: The emission of acyclic homoterpenes from leaves of Phaseolus lunatus and Zea mays can be triggered by a $\beta$-glucosidase and jasmonic acid. FEBS (Fed. Eur. Biochem. Soc.) Lett. 352:146-150.

Karban, R., and Baldwin, I. T. 1997. Induced Responses to Herbivory. University of Chicago Press, Chicago.

Larson, K. C. 1998. The impact of two gall-forming arthropods on the photosynthetic rates of their hosts. Oecologia 115:161-166. 
Leech, R. M., Rumsby, M. G., and Thomson, W. W. 1973. Plastid differentiation, acyl lipid, and fatty acid changes in developing green maize leaves. Plant Physiol. 52:240-245.

Maddox, G. D., and Root, R. B. 1990. Structure of the encounter between goldenrod (Solidago altissima) and its diverse insect fauna. Ecology 71:2115-2124.

McCloud, E. S., and Baldwin, I. T. 1997. Herbivory and caterpillar regurgitants amplify the wound-induced increase in jasmonic acid but not nicotine in Nicotiana sylvestris. Planta 203:430-435.

Miller, M. E. 2000. A comparative taxonomic-natural history study of eight Neartic species of Gnorimoschema that induce stem galls on Asteraceae, including descriptions of three new species (Lepidoptera: Gelechiidae). Thomas Say Publication in Entomology: Monographs. Entomological Society of America, Lanham. MD, U.S.A.

Mopper, S., Wang, Y., Criner, C., and Hasenstein, K. 2004. Iris hexagona hormonal responses to salinity stress, leafminer herbivory, and phenology. Ecology 85:38-47.

Motta, L. B., Kraus, J. E., Salatino, A., and Salatino, M. L. F. 2005. Distribution of metabolites in galled and non-galled foliar tissues of $\mathrm{Ti}$ bouchina pulchra. Biochem. Syst. Ecol. 33:971-981.

Nyman, T., and Julkunen-Tiitto, R. 2000. Manipulation of the phenolic chemistry of willows by gall-inducing sawflies. Proc. Natl. Acad. Sci. U.S.A. 97:13184-13187.

Ollerstam, O., and Larsson, S. 2003. Salicylic acid mediates resistance in the willow Salix viminalis against the gall midge Dasineura marginemtorquens. J. Chem. Ecol. 29:163-174.

Price, P. W., Fernandes, G. W., and Waring, G. L. 1987. Adaptive nature of insect galls. Environ. Entomol. 16:15-24.

Raman, A., Schaefer, C. W., Withers, T. M. 2005. Galls and gall-inducing arthropods: An overview of their biology, ecology and evolution. Pages 1-33 in: Biology, Ecology, and Evolution of Gall-inducing Arthropods. A. Raman, C. W. Schaefer, and T. M. Withers, eds. Science Publishers, Enfield, CT, U.S.A.

SAS Institute. 2003. SAS/STAT User's Guide for Personal Computers, release 9. SAS Institute, Cary, NC, U.S.A.

Schmelz, E. A., Engelberth, J., Alborn, H. T., O’Donnell, P., Sammons, M., Toshima, H., and Tumlinson, J. H. 2003. Simultaneous analysis of phytohormones, phytotoxins, and volatile organic compounds in plants. Proc. Natl. Acad. Sci. U.S.A. 100:10552-10557.

Schmelz, E. A., Engelberth, J., Tumlinson, J. H., Block, A., and Alborn, H. T. 2004. The use of vapor phase extraction in metabolic profiling of phytohormones and other metabolites. Plant J. 39:790-808.

Sokal, R. R., and Rohlf, F. J. 1995. Biometry, 3rd edition. W. H. Freeman $\&$ Co., New York.

Stone, G. N., and Schönrogge, K. 2003. The adaptive significance of insect gall morphology. Trends Ecol. Evol. 18:512-522.

Thomas, F., Schmidt-Rhaesa, A., Martin, G., Manu, C., Durand, P., and Renaud, F. 2002. Do hairworms (Nematomorpha) manipulate the water seeking behaviour of their terrestrial hosts J. Evol. Biol. 15:356-361.

Tooker, J. F., and De Moraes, C. M. 2007. Feeding by Hessian fly [Mayetiola destructor (Say)] larvae does not induce plant indirect defences. Ecol. Entomol. 32:153-161.

Tooker, J. F., and De Moraes, C. M. 2008. Gall insects and indirect defenses: A case of active manipulation? Plant Sig. Behav. 3:503-504.

Tooker, J. F., and Hanks, L. M. 2004. Stereochemistry of host plant monoterpenes as mate location cues for the gall wasp Antistrophus rufus. J. Chem. Ecol. 30:473-477.

Tooker, J. F., and Hanks, L. M. 2006. Tritrophic interactions and reproductive fitness of the prairie perennial Silphium laciniatum Gillette (Asteraceae). Environ. Entomol. 35:537-545.

Tooker, J. F., Koenig, W. A., and Hanks, L. M. 2002. Altered host plant volatiles are proxies for sex pheromones in the gall wasp Antistrophus rufus. Proc. Natl. Acad. Sci. U.S.A. 99:15486-15491.

Tooker, J. F., Rohr, J. R., Abrahamson, W. G., and De Moraes, C. M. 2008. Gall insects can avoid and alter indirect plant defenses. New Phytol. 178:657-671.

Turlings, T. C. J, Tumlinson, J. H., and Lewis, W. J. 1990. Exploitation of herbivore-induced plant odors by host-seeking parasitic wasps. Science 250:1251-1253.

Turlings, T. C. J., Bernasconi, M., Bertossa, R., Bigler, F., Caloz, G., and Dorn, S. 1998. The induction of volatile emissions in maize by three herbivore species with different feeding habits: Possible consequences for their natural enemies. Biocontrol 11:122-129.

Vanderzant, E. S. 1968. Dietary requirements of the bollworm, Heliothis zea (Lepidoptera: Noctuidae) for lipids, choline, and inositol, and the effects of fats and fatty acids on the composition of body fat. Ann. Entomol. Soc. Am. 61:120-125.

Walling, L. L. 2000. The myriad plant responses to herbivores. J. Plant Grow. Reg. 19:195-216.

Ziegler, J., Keinänen, M., and Baldwin, I. T. 2001. Herbivore-induced allene oxide synthase transcripts and jasmonic acid in Nicotiana attenuata. Phytochemistry 58:729-738. 